\title{
Teaching Electrolysis in a way that Enhances Problem Solving, Analytical and Communicative Skills
}

\author{
Shenelle Pearl Ghulam \\ Chemistry Teacher Education Unit, University of Helsinki • shenelle.ghulam@helsinki.fi
}

\begin{abstract}
Problem solving is central in chemical education. In order to succeed as a chemistry student or professionally as a chemist it is highly crucial to develop skills that enhance problem solving. Prioritizing the development of problem solving a lesson on electrolysis was planned for 11th graders. This article presents significant teaching and learning methods that according to research enhance problem solving and other related skills. Additionally the article presents successful applications of these methods into teaching electrolysis concepts. The methods introduced are solving problems cooperatively in groups, solving problems with students rather than for students, the use of animations and provoking class participation and discussion.
\end{abstract}

\section{Introduction}

Problem solving plays a prominent role in chemistry education. It is not enough for students to merely solve exercises based on learned procedures. True problem solving requires the use of critical and analytical skills in order to solve a problem that is subject to a specific set of conditions that the problem solver has not seen before, in order to obtain a satisfactory solution.

After much research and planning, a lesson plan on electrolysis was designed in order to specifically enhance student problem solving and analytical skills. Additional aims were to develop student communicative skills and to instill a deep understanding of the concepts of electrolysis. The lesson was designed for students taking the fourth chemistry course in a bilingual Finnish high school.

\section{Electrolysis}

Electrolysis has very important and fascinating applications in the world today. These applications include: gold plating, purification of copper, many industrial processes and the separation of water into hydrogen and oxygen in order to provide astronauts with oxygen to breath.

Electrolysis is a process by which substances are broken down when an electric current is passed through them. These reactions are called non-spontaneous as they require external energy. Non-spontaneous reactions such as $2 \mathrm{NaCl}(\mathrm{l}) \rightarrow 2 \mathrm{Na}(s)+\mathrm{Cl}_{2}(g)$ occur in electrolytic cells. Figure 1 below shows the structure of an electrolytic cell for this particular reaction. 


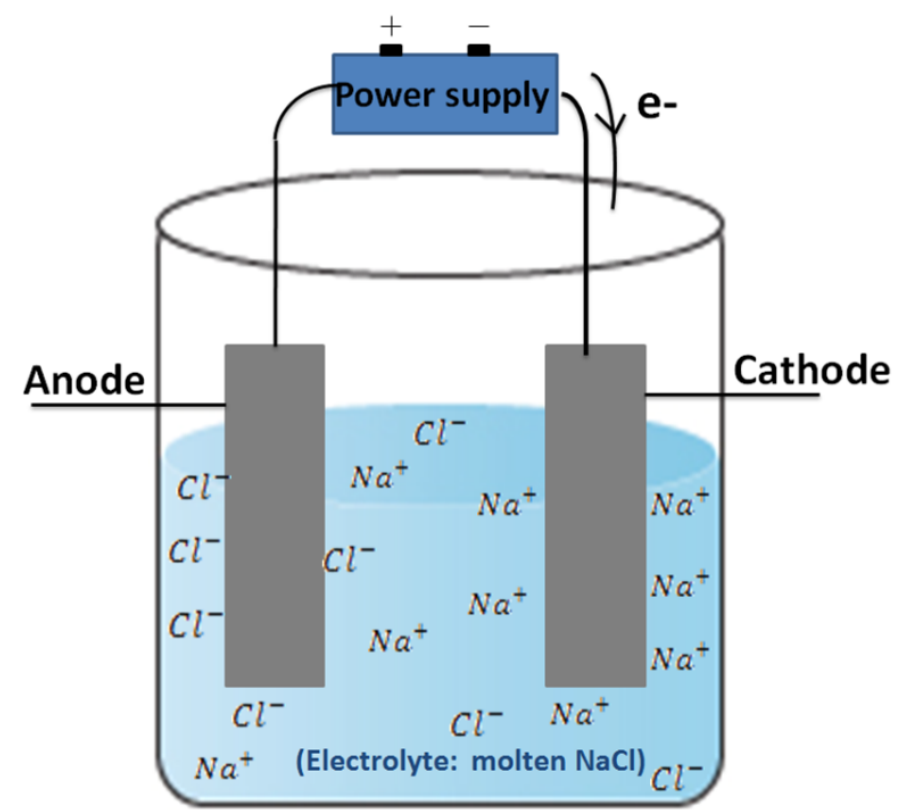

Figure 1 An electrolytic cell for the non-spontaneous reaction of aqueous $\mathrm{NaCl}$ producing solid sodium at the cathode and gaseous chlorine at the anode.

\subsection{Predicting the products of electrolysis}

Predicting the products of electrolysis is rather simple. It is essential to remember that at the cathode positively charged ions gain electrons (reduction) and at the anode negatively charged ions loose electrons (oxidation). For example in the case of molten sodium chloride:

$$
\begin{array}{ll}
\mathrm{Na}^{+}+e^{-} \rightarrow \mathrm{Na}(\mathrm{s}) & \text { (reduction at the cathode) } \\
\mathrm{Cl}^{-} \rightarrow \mathrm{Cl}_{2}(\mathrm{~g})+e^{-} & \text {(oxidation at the anode) }
\end{array}
$$

However, the case becomes more complicated if one is predicting the products of electrolysis of an aqueous solution of sodium chloride. In that case one would need to consider the possibility of water being oxidized or reduced as well.

Possible reduction reactions:

$$
\begin{array}{lr}
2 \mathrm{H}_{2} \mathrm{O}(\mathrm{l})+2 e^{-} \rightarrow \mathrm{H}_{2}(\mathrm{~g})+2 \mathrm{OH}^{-}(\mathrm{aq}) & E_{p}=-0,83 \mathrm{~V} \\
\mathrm{Na}^{+}+e^{-} \rightarrow \mathrm{Na}(\mathrm{s}) & E_{p}=-2,71 \mathrm{~V}
\end{array}
$$

Possible oxidation reactions:

$$
\begin{array}{ll}
2 \mathrm{H}_{2} \mathrm{O}(l) \rightarrow 4 \mathrm{H}^{+}(a q)+\mathrm{O}_{2}(g)+4 e^{-} & E_{h}=1,23 \mathrm{~V} \\
2 \mathrm{cl}^{-}(a q) \rightarrow \mathrm{Cl}_{2}(\mathrm{~g})+2 e^{-} & E_{h}=1,36 \mathrm{~V}
\end{array}
$$

Since the reduction of water has a greater electrode potential than the reduction of $\mathrm{Na}^{+}$ one would expect that it would be easier for water to accept electrons; thus water is reduced at the cathode. Similarly since the oxidation of water has a smaller electrode potential than the oxidation of $\mathrm{Cl}^{-}$one would expect that it would be easier for to remove electrons from water; thus water is oxidized at the anode. 


\subsection{Quantitative electrolysis}

Michael Faraday was a well accomplished British Chemist and Physicist who contributed significantly to the study of electromagnetism and electrochemistry. Faradays laws of electrolysis are the basis for quantitative calculations of electrolysis. His laws are summed up in the equation $I t=n z F$. Where $\mathrm{I}$ is current in amperes, $\mathrm{t}$ is time in seconds, $\mathrm{n}$ is amount of substance released at the electrode in moles, $\mathrm{z}$ is electrons transferred per ion and $\mathrm{F}$ is Faradays constant $\left(96485 \mathrm{C} \mathrm{mol}^{-1}\right)$. With the mentioned equation electrolysis can be quantified. (Kaila, Meriläinen, Pihko \& Ojala, 2012; Lehtiniemi \& Turpeenoja, 2011; Nivaldo, 2011)

\section{Teaching Methods Based on Research}

\subsection{Teaching Methods for Quantitative Problem Solving}

Problem solving is a crucial component of most sciences including chemistry. Unfortunately, many students tend to find problem solving rather challenging. While generally problem solving in chemistry can prove to be challenging, additional problems arise when solving the problem involves some form of calculations. Numerous researches have been conducted to further understand and develop teaching methods, skills and activities that boost productive problem solving. This section contains two significant teaching methods to enhance problem solving skills in students.

\subsubsection{Group Work}

Several researches have indicated that students are more productive when working together in groups, by in class group discussions, or by cooperative learning activities. Working in groups improves students' attitudes towards learning and motivation (Ross \& Fulton, 1994). Class discussions improve students reasoning and problem solving skills (Fasching \& Erickson, 1985). Cooperative learning reduces frustration and anxiety and causes students to be more persistent (Tingle \& Good, 1990).

\subsubsection{Solving Problems With Students Rather than For Students}

Many teachers introduce students to calculation based problem solving related to a specific topic by, presenting them with a couple of example problems and solving it for them. The teacher then expects the students to solve similar problems and calculate results using the example problems and calculations for support. This encourages students to search for algorithms that fit the problem and to try and apply the algorithm in a similar method as the teacher. This is problematic as students then proceed to solve problems without critically analyzing and understanding the problem themselves (Gilbert, Jong, Justi, Treagust \& Van Driel, 2002) Frank, Baker and Herron (1987) discovered a solution for this problem. Their solution was that the teacher could involve the students in the problem solving process effectively solving the problem with the students. Rather than showing the 
students how to solve a problem, the teacher could get the students opinions on how they think it should be done. The teacher could start by gathering ideas on how to solve the problem, and then ask the students to explain step by step how to proceed. The teacher could also help the students out a bit if needed; thus solving the problem together. This encourages the students to apply rather than remember and provides them with diverse perspectives on problem solving.

\subsection{Teaching Methods to Facilitate a Deeper Understanding of Chemistry}

It is of the utmost importance for students to understand, retain and be able to apply the concepts of chemistry. There are a plethora of methods used to achieve such an effect. This section contains two significant teaching methods used to facilitate a deeper understanding of chemistry.

\subsubsection{Animations}

Students retain more information, learn concepts more rapidly, and are more motivated and more enthusiastic, when learning material is provided to them in the form of an animation or video. Additionally animations also facilitate students' ability to make connections among the macroscopic, submicroscopic and symbolic levels of representations. Therefore the use of animations could assist students in acquiring a deeper understanding of the concept in question. (Ashkenazi, Tasker, Velazquez-Marcano, Williamson \& Williamson, 2004)

\subsubsection{Provoking Class Participation and Discussion while Lecturing}

According to the learning pyramid in figure 2, a typical lecture only has a less than $10 \%$ retention rate of information. However, discussion contributes to $50 \%$ retention of information. Therefore, including discussion, during lessons could be beneficial.

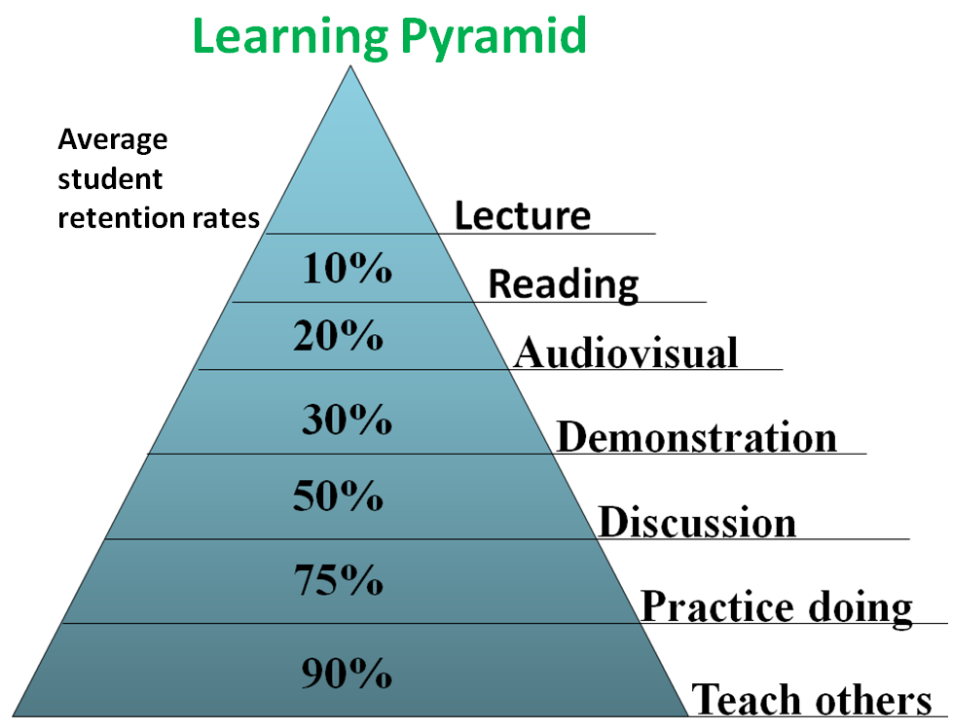

Figure 2 The learning pyramid (National Training Laboratories, Bethel, Maine) 


\section{Applications of Teaching Methods in the Electrolysis Lesson Plan}

\subsection{Provoking Class Participation and Discussion while Lecturing}

Integrating a lecture and discussions could ensure that students retain more information from the lecture. In order to enhance students' retention of concepts, class discussions and participation could be encouraged during lectures as well. Using discussion during a lecture could also help students feel more involved and interested in the lecture. According to the lesson plan provoking class participation and discussion during the lecture on electrolysis is achieved by asking students a couple of questions while lecturing. Questions such as:

- About previously covered topics related to the current topic. For example: what is oxidation or reduction? What are the differences you notice between an electrolytic and galvanic cell?

- About the meaning of certain English chemical terms in Finnish, as the lesson was designed ideally for a bilingual class. For example: What is oxidation or reduction in Finnish? What is an electrolytic cell called in Finnish?

\subsection{Animations}

The design of the lesson is such that after the lecture, a 7 minute animation video is shown to the students. The video serves as a way to review with them what they have just been taught, since research shows that repeating information consecutively could assist students to retain information well. It also further introduces the uses of electrolysis. The video is funny and interesting which should increase student motivation and attention; it also could facilitates students in retaining more information, and learning concepts more rapidly.

The animation video used was extracted from BBC Bitesize collection.

\subsection{Solving Problems With rather than For Students}

According to the lesson plan teaching students how to solve problems using the formula If $=\mathrm{nzF}$, is achieved by solving an example question with the students rather than for them. For example, solve one simple problem with the students, this could be done in 2 steps: first allow the students the time to think about what should be done on an individual basis. The teacher could go around providing help if necessary. The idea of giving individual time is so that it's not just the 'quicker' students that figure it out and tell the rest of the class but that the entire class has time to figure it out on their own. The second step would then be that having gone around the class making sure that each student has at least thought about it the question. The teacher could then ask the students to solve the problem together as a class, allowing them to indicate to the teacher step by step what they would like to write on the whiteboard or allowing them to come write it up themselves. 


\subsection{Group Work}

The group work designed for the lesson is based on the Jigsaw classroom (Eilks, Prins \& Lazarowitz, 2013) and is meant for a class of 17 students.

- Group work Phase One (20 min). Divide the class into 4 groups. Give each group 1 question each to solve, in such a way that group 1 gets question 1 , group 2 gets question 2 etc... The idea being that they solve the question cooperatively, by contributing ideas. The teacher must go around making sure that each group has solved the question correctly before continuing to the next phase of the group work.

- Group work Phase Two (20 min). The second part of the group work is carried out in such a way that the students get shuffled around into new groups in such a way that each new group consists of one person from question 1, one person from question 2 etc... The switch should occur as shown in the figure 3 below. The image could be shown to the students to avoid confusion.

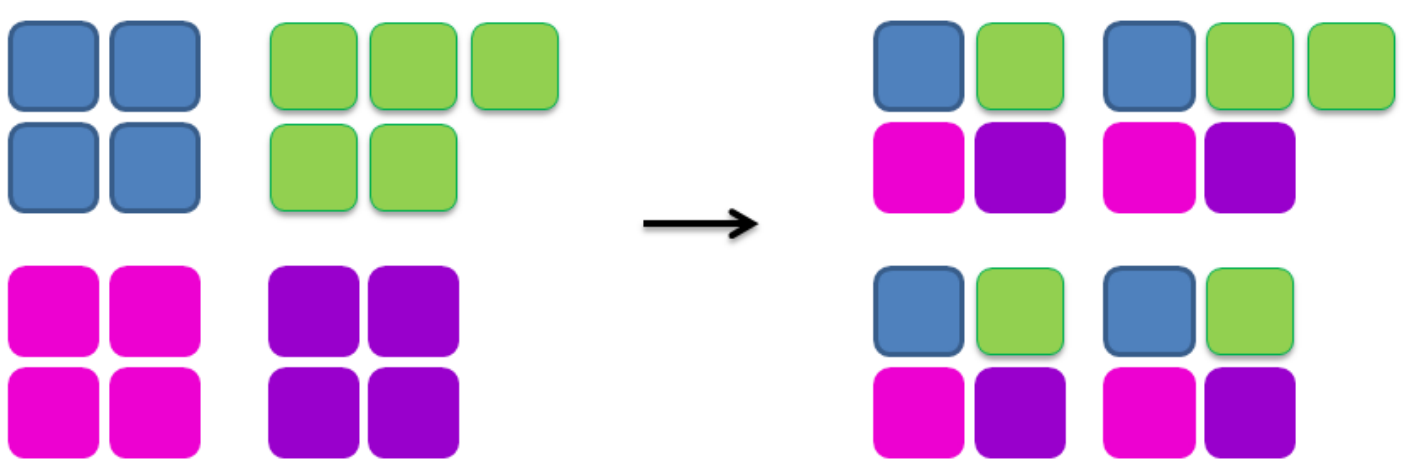

\section{0 minutes 20 minutes}

Figure 3 Group work organization according to Jigsaw classroom.

The idea of the second round is that each student should be an expert of the question that they solved in the first round. Then each student should explain to the rest of their current group how the question was solved explaining it in a clear way so that their peers understand while at the same time trying to present the diverse perspectives of problem solving that might have come up while seeking a solution. This step will ensure that all students contribute and try to truly understand the question that they are solving as they know that they will have to explain the question to their peers later. Explaining the problem to one's peers also helps one understand it better themselves, as shown in the learning pyramid (figure 2) there is a 90\% average retention rate when teaching others. Also this way many students will be able to acquire many different perspectives of problem solving, enhancing their problem solving analytical, social and communicative skills. 


\section{References}

Ashkenzi, G., Tasker, R., Velazquez-Marcano, A., Williamson, K. C. \& Williamson, V. M. 2004. The Use of Video Demonstrations and Particulate Aniation in General Chemistry. Journal of Science Education and Technology, 13(3), 315-323.

Eilks, I., Prins, G. T. \& Lazarowitz, R. (2013). How to promote chemistry classroom in a studentactive mode. In I. Eilks \& A. Hofstein (Eds), Teaching Chemistry - A Studybook: A Practical Guide and Textbookfor Student Teachers, Teacher Trainees and Teachers. Rotterdam: Sense Publishers.

Fasching, J.L., \& Erickson, B.L. (1985). Group discussions in the chemistry classroom and the problem-solving skills of students. Journal of Chemical Education,62(10), 842-848.

Frank, D.V., Baker C.A., \& Herron, J.D. (1987). Should students always use algorithms to solve problems? Journal of Chemical Education, 64(6), 514-515

Gilbert, J.K., Jong, O.D., Justi, R., Treagust, D.F. \& Van Driel, J.H. (2002). Chemical Education: Towards Research-based Practice. p 235-266. Dordrecht: Kluwer Academic Publishers.

Kaila, L., Meriläinen, P., Pihko, P. \& Ojala, P. (2012). Reaktio 4 : Metallit ja materiaalit. Helsinki: Sanoma Pro.

Lehtiniemi, K. \& Turpeenoja, L. (2011). Mooli 4: Metallit ja materiallit. Helsinki: Otava.

Nivaldo, J. T. (2011). Chemistry a molecular approach. New Jersey: Pearson.

Ross, M. \& Fulton, R. (1994). Active learning strategies in the analytical chemistry classroom. Journal of Chemical Education, 71(2), 141-143.

Tingle, J.B., \& Good, R. (1990). Effects of cooperative grouping on stoichiometric problemsolving in high school chemistry. Journal of Research in Science Teaching, 27(7), 671-683. 